\title{
An Experimental and Theoretical Study on the Structural Properties of $N^{\prime}$-[ $(E)$-(5-chloro-2-hydroxyphenyl)methylidene] acetohydrazide
}

\author{
A.V. Aparna ${ }^{1}$, D. A. Padmavathy ${ }^{2}$ and Ch. Sarala Devi ${ }^{3}$ \\ 1. Department of Chemistry, Nizam College, Osmania University, Basheerbagh, Hyderabad \\ 2. Department of Chemistry, Post Graduate College of Science, Saifabad, Osmania University, Hyd \\ ${ }^{3}$ Department of Chemistry, University College of Science, Osmania University, Hyderabad
}

\begin{abstract}
The structural properties of $N^{\prime}-[(E)-(5$-chloro-2-hydroxyphenyl)methylidene]acetohydrazide (NClHMAH) have been investigated by spectro-analytical and computational studies. ChemAxon and HyperChem 7.5 tools were employed to generate energy parameters, heat of formation, dipole moment values. Molecular orbital calculations were performed with quantum mechanics based semi empirical Parametric Method 3 (PM3). The compound NClHMAH was characterized by elemental analyses, $I R,{ }^{1} \mathrm{H}-\mathrm{NMR},{ }^{13} \mathrm{C}-$ NMR, DEPT and Mass spectral data. The equilibrium studies were carried out to determine the dissociation constants of NClHMAH in $70 \% \mathrm{v} / \mathrm{v} \mathrm{DMF}$ - water medium at $303 \mathrm{~K}$ and $0.1 \mathrm{M}\left(\mathrm{KNO}_{3}\right)$ ionic strength adopting pH-metric technique. The dissociation of two protons is evident from these studies indicating it as a dibasic acid. The microbial studies affirmed moderate antibacterial activity of NClHMAH against Staph. Aureus and the compound is resistant to E.Coli. while its copper complex has exhibited enhanced anti-bacterial activity for both the cultures.
\end{abstract}

Keywords: $N$ '-[(E)-(5-chloro-2-hydroxyphenyl)methylidene]acetohydrazide(NClHMAH), computational studies, equilibrium studies, mass, $I R,{ }^{1} \mathrm{H}-N M R,{ }^{13} \mathrm{C}-N M R, D E P T$.

\section{Introduction}

Hydrazides and hydrazones have been demonstrated to possess anti-microbial, anti-convulsant, analgesic, anti-inflammatory and anti-tumorial activities[1]. The acid hydrazides and their corresponding methyl hydrazides are of interest due to their remarkable biological activity. Acetyl hydrazones are known to posses good protection against convulsions [2]. The present study investigates the structural properties of N'-[(E)-(5-chloro-2-hydroxyphenyl)methylidene]acetohydrazide (NClHMAH), by various spectro - analytical techniques viz; mass, IR, UV, ${ }^{1} \mathrm{H}-\mathrm{NMR},{ }^{13} \mathrm{C}-\mathrm{NMR}$, DEPT and $\mathrm{pH}-$ metry. Computational studies using ChemAxon and Hyperchem 7.5 have been carried out to calculate the energy parameters, heat of formation, dipole moments and energies of HOMO and LUMO orbitals. Equilibrium studies have been carried out on the title compound in $70 \% \mathrm{v} / \mathrm{v}$ DMF - water medium at $303 \mathrm{~K}$ and $0.1 \mathrm{M}\left(\mathrm{KNO}_{3}\right)$ ionic strength adopting $\mathrm{pH}$-metric technique to determine number of dissociable protons.

\section{Experimental}

All the chemicals used were of Analytical Reagent (A.R) grade. The synthesis of N'-[(E)-(5-chloro-2hydroxyphenyl)methylidene]acetohydrazide includes two steps - Preparation of Acetohydrazide following the literature methods [3] and in subsequent step its conversion to title compound (NClHMAH). A yellow coloured solid of NClHMAH separated out by adding $0.0032 \mathrm{~mol}$ of chlorosalicylaldehyde to a suspension of $0.0135 \mathrm{~mol}$ of acetohydrazide in $20 \mathrm{~mL}$ methanol, and then refluxing it for $2 \mathrm{hrs}$. The solid obtained was filtered, washed with methanol, dried and recrystallized from methanol. The compound was separated out as a lemon yellow crystalline solid. The purity of the compound was checked by TLC, LC-MS and melting point.

Synthesis of Copper complex is facilitated by adding a solution of $\mathrm{Cu}$ (II) metal $(0.00118 \mathrm{~mol})$ to a hot methanolic solution of NClHMAH $(0.0024 \mathrm{~mol})$, in 1:2 molar ratio. The $\mathrm{pH}$ of the mixture is adjusted to enable dissociation of protons and subsequent binding of metal ion with the title compound. The reaction mixture was refluxed for about $6-7$ hours. The metal complex separated was filtered and washed with hot methanol, petroleum ether and finally air dried. The resulting metal complex was characterized by mass, IR, elemental analyses and thermo - analytical techniques. Anti - bacterial studies were also carried out on the title compound and its copper (II) complex.

III. Physical Measurements

Elemental analyses, IR, NMR and mass spectral studies were used for characterization. Mass spectral data were recorded on Schimadzu LCMS - 2010A using atmospheric pressure chemical ionization in positive 
mode. IR spectra $(\mathrm{KBr})$ were recorded on a JASCO FT/IR - 5300 and the CHN elemental data were recorded on FLASH EA 1112 Series Thermofinnigan. ${ }^{1} \mathrm{H}$ and ${ }^{13} \mathrm{C}$ NMR spectra were recorded on ACF 200, BRUKER, WestGermany SUPER CONDUCTIVITY MAGNET. The equilibrium studies were carried out on a digital Digisun $707 \mathrm{pH}$-meter with an assembly of combined glass electrode maintaining the temperature constant. The dissociation constant of the ligand under study was calculated using Irving - Rossotti titration technique.

\section{Computational Studies}

The computational studies were carried out by using Chemaxon[4] and HyperChem 7.5 [5] software. The energies of various conformers, heats of formation, energies, dipole moments, eigen values of HOMO \& LUMO and QSAR properties are computed from these studies.

\subsection{Spectral Characterization of the hydrazone \\ 5.1.1 Mass spectral data}

\section{Results \& Discussion}

The LC chromatogram of N'-[(E)-(5-chloro-2hydroxyphenyl)methylidene]acetohydrazide showed a single peak at 0.657 mins (positive mode) (Fig 1).

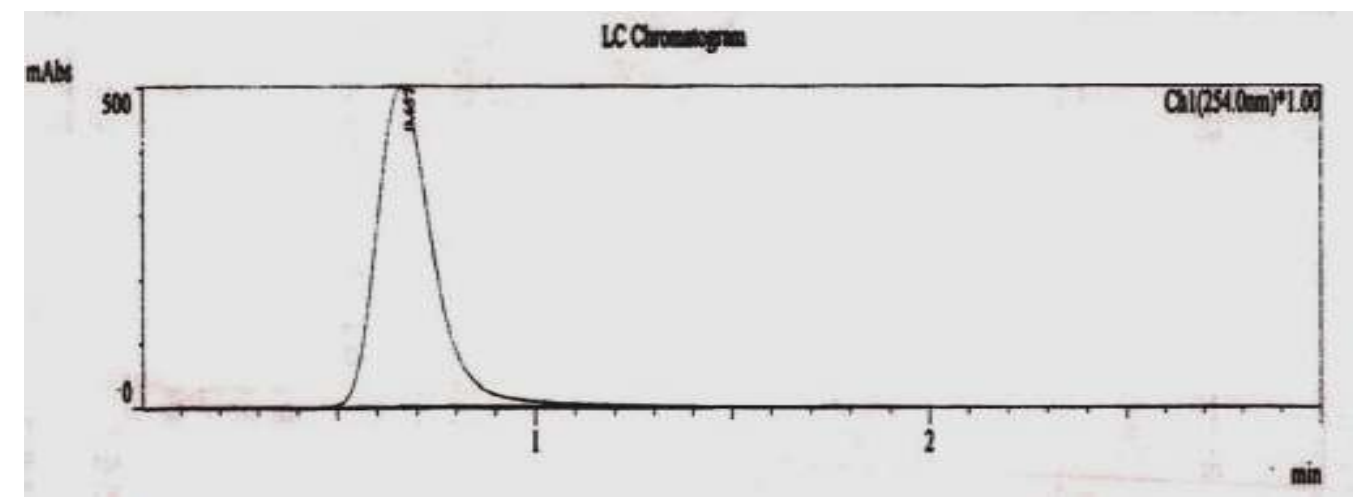

Figure 1 LC Chromatogram of NClHMAH

The mass spectral data of NClHMAH, under positive ionization conditions recorded peaks at $\mathrm{m} / \mathrm{z} 213$ and 215, which correspond to $[\mathrm{M}+1]^{+}$and $[\mathrm{M}+2]^{+}$ions respectively. A base peak observed at $\mathrm{m} / \mathrm{z} 235$ and a peak at $\mathrm{m} / \mathrm{z} 237$ were ascribable to sodium adduct ions $[\mathrm{M}+23]^{+}$and $[\mathrm{M}+23+2]^{+}($Fig 2$)$.

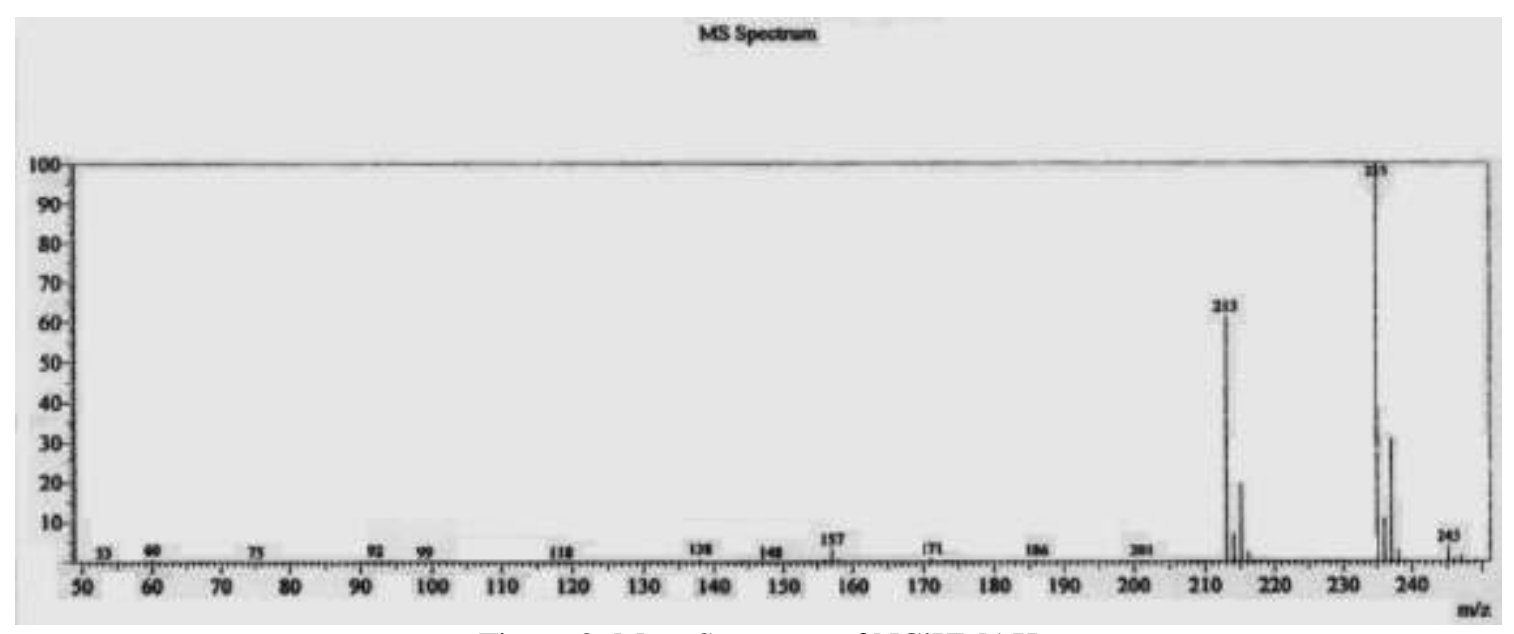

Figure 2 Mass Spectrum of NClHMAH

\subsubsection{IR spectral data}

The IR spectrum of NCIHMAH (Fig 3) showed bands at 3836, 3194, 3082, 2964, 2945, $2904 \mathrm{~cm}^{-1}$ attributable to $v_{\mathrm{O}-\mathrm{H}}, v_{\mathrm{C}-\mathrm{H}(\text { aliphatic) }}$ and $v_{\mathrm{C}-\mathrm{H}(\text { aromatic). }}$ A strong peak at $1664 \mathrm{~cm}^{-1}$ corresponds to the carbonyl group of CONH. The $v_{\mathrm{C}-\mathrm{H}}$ azomethine band is observed at $2886 \mathrm{~cm}^{-1}$ and $v_{\mathrm{C}=\mathrm{N}}$ band at $1627 \mathrm{~cm}^{-1}$. Peaks at 1479 and $1396 \mathrm{~cm}^{-1}$ are characteristic of the methyl group bending modes and a strong band at $815 \mathrm{~cm}^{-1}$ indicates the presence of para - substituted aromatic ring. 
A comparison between the experimental values and the theoretical values obtained by semi - empirical PM3 method using HyperChem 7.5 affirmed good agreement (TABLE -1).

Table 1: Comparison of the IR spectral data obtained experimentally and by using semi - empirical PM3

\begin{tabular}{|c|c|c|c|c|c|c|}
\hline \multicolumn{7}{|c|}{ od } \\
\hline Methods & $\begin{array}{l}v_{\mathrm{O}-\mathrm{H}} \\
\mathrm{cm}^{-1}\end{array}$ & $\begin{array}{c}v_{\mathrm{C}-\mathrm{H}(\mathrm{CH} 3)} \\
\mathbf{c m}^{-1}\end{array}$ & $\begin{array}{c}v_{\mathrm{C}-\mathrm{H}(\text { aromatic })} \\
\mathrm{cm}^{-1}\end{array}$ & $\begin{array}{c}v_{\mathrm{C}-\mathrm{H}(\text { azomethine })} \\
\mathrm{cm}^{-1}\end{array}$ & $\begin{array}{l}v_{\mathrm{CONH}} \\
\mathrm{cm}^{-1}\end{array}$ & $\begin{array}{l}v_{\mathrm{C}=\mathrm{N}} \\
\mathrm{cm}^{-1}\end{array}$ \\
\hline Experimental & 3836 & $\begin{array}{l}3194 \\
3082\end{array}$ & $\begin{array}{c}2964,2945 \\
2904\end{array}$ & 2866 & 1664 & 1620 \\
\hline Computational & 3883 & $\begin{array}{l}3178, \\
3082\end{array}$ & $\begin{array}{c}3068,3051 \\
3032\end{array}$ & 2960 & 1938 & 1627 \\
\hline
\end{tabular}

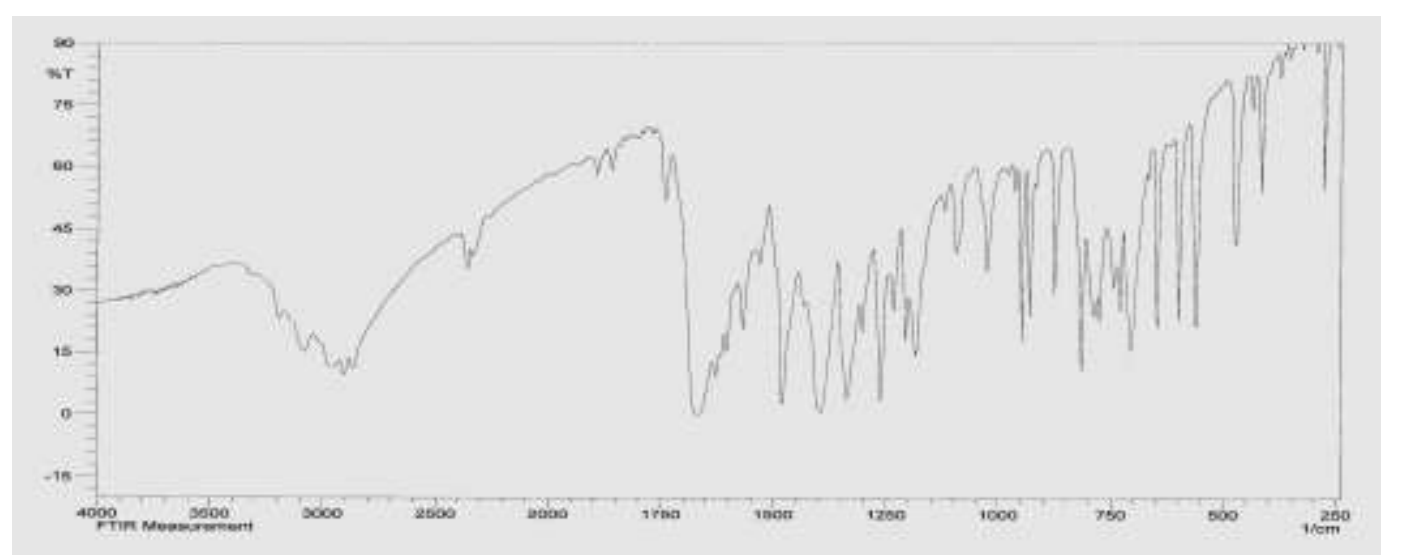

Figure 3 IR spectrum of NClHMAH

\subsubsection{NMR}

The ${ }^{1} \mathrm{H}$ - NMR spectrum of NClHMAH in $\mathrm{CDCl}_{3}+\mathrm{DMSO}-\mathrm{d}_{6}$ recorded signals at $\delta 1.94,2.13,2.51$ $\left(\mathrm{CH}_{3}\right), \quad \delta 6.74-8.08$ (m, aromatic $\left.\mathrm{CH}\right), \delta 8.56$ (s, azomethine), $\delta 10.90-11.22$ for $\mathrm{OH}$ and $\delta 10.35$ for $\mathrm{NH}$. The $\mathrm{OH}$ and $\mathrm{NH}$ peaks are readily identified by recording $\mathrm{D}_{2} \mathrm{O}$ exchange spectrum (Fig 4). The split in $\mathrm{CH}_{3}$ signal and presence of more number of signals than expected indicates the existence of conformers of NClHMAH.

The quantum mechanical calculations for $\mathrm{NClHMAH}$ showed NMR signals at $\delta 2.52$ for $\mathrm{CH}_{3}, \delta 6.76$ - 7.21 for aromatic protons, $\delta 12.97$ and 13.27 for $\mathrm{OH}$ and $\mathrm{NH}$ respectively. Thus, the ${ }^{1} \mathrm{H}-\mathrm{NMR}$ spectral data of the ligand obtained experimentally was comparable with the data obtained by semi - empirical PM3 method.

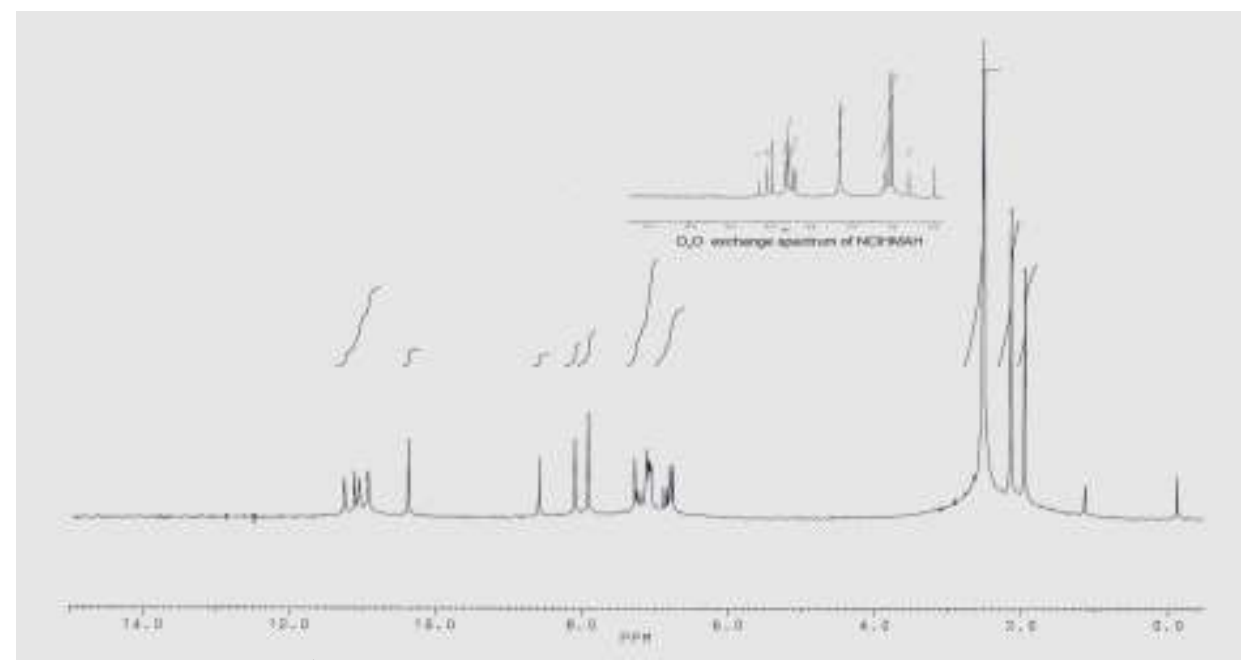

Figure $4{ }^{1} \mathrm{H}-\mathrm{NMR}$ and $\mathrm{D}_{2} \mathrm{O}$ Exchange Spectrum of NClHMAH

The ${ }^{13} \mathrm{C}-\mathrm{NMR}$ spectrum (Fig 5) in $\mathrm{CDCl}_{3}+\mathrm{DMSO}-\mathrm{d}_{6}$ mixture also showed a complex spectrum with more number of peaks than expected $(20.27,21.26,117.82,118.10,119.29,128.42,129.07,130.47$, $143.37,146.50,155.69,156.55,165.93 \mathrm{ppm})$. This indicates the existence of the compound as different conformational isomers. 


\subsubsection{DEPT}

The Distortionless Enhancement by Polarization Technique (DEPT) technique determines the number of hydrogen atoms attached to carbon atoms. The DEPT 45 and 135 recorded $\mathrm{CH}$ and $\mathrm{CH}_{3}$ signals and DEPT 90 recorded $\mathrm{CH}$ signals (Fig 5). DEPT 45 and 135 recorded 10 signals (two for $\mathrm{CH}_{3}$ at 20.33, $21.27 \mathrm{ppm}$ and 8 for $\mathrm{CH}$ at $117.7,118.05,128.26,129.00,130.26,130.45,143.17$ and $146.34 \mathrm{ppm})$ instead of 5 signals where as DEPT 90 recorded 8 signals at $117.76,118.04,128.23,128.99,130.25,130.44,143.12,146.31 \mathrm{ppm}$ instead of 4 signals. The presence of more number of signals than expected indicates the existence of conformational isomerism in NClHMAH.

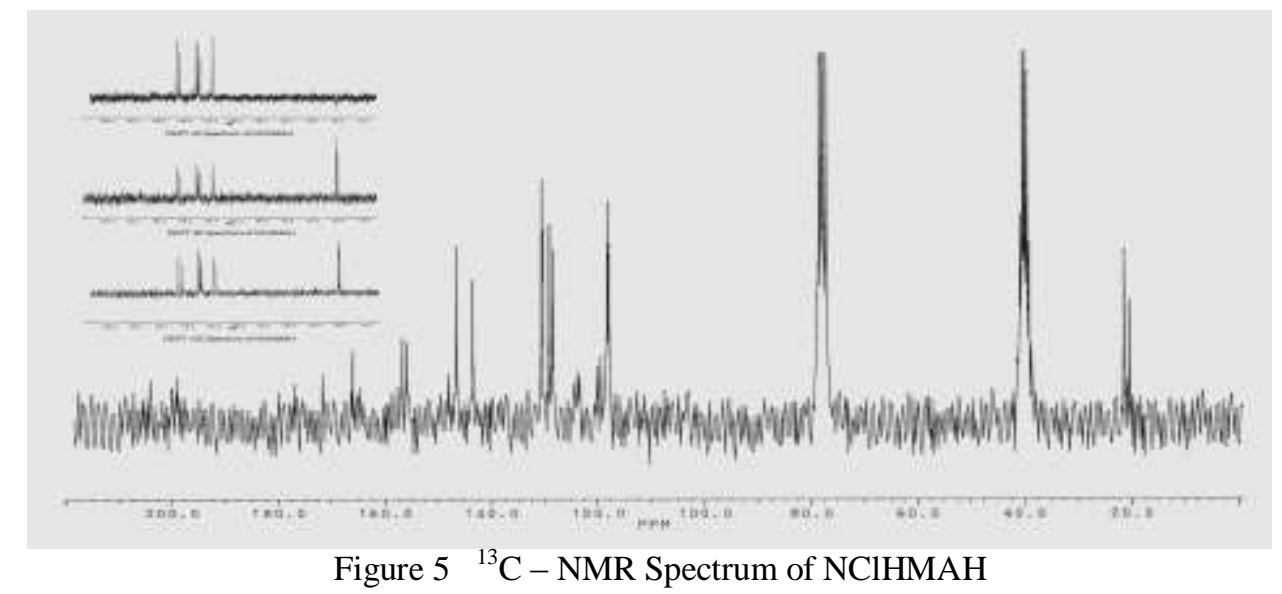

\subsubsection{Equilibrium Studies}

The proton - ligand constants $\left(\mathrm{pK}_{\mathrm{a}}\right)$ of the title compound have been evaluated by analysing the $\mathrm{pH}$ titration curves obtained using the Irving - Rossotti method [6]. The potentiometric titrations were carried out in $70 \%$ DMF - water medium at $303 \mathrm{~K}$ and $0.1 \mathrm{M}\left(\mathrm{KNO}_{3}\right)$ ionic strength. The studies revealed that there are two dissociable protons in the ligand, one at 9.1 and the other at 11.0 (Fig 6). The lower $\mathrm{pK}_{\mathrm{a}}$ value corresponds to dissociation of proton from hydroxyl group on the phenyl ring and the higher $\mathrm{pK}_{\mathrm{a}}$ value corresponds to the dissociation of proton from the amide group. The $\mathrm{NH}$ proton dissociation either takes place from nitrogen itself or from oxygen via enol form. But earlier studies [7] have supported that dissociation via enol form through oxygen is easier as the proton acquires relatively more acidic character in enol form compared to keto form.

The molecule was built using ChemAxon software and the $\mathrm{pK}_{\mathrm{a}}$ values were computed. The data obtained indicated the presence of two dissociable protons with $\mathrm{pK}_{\mathrm{a}}$ values 8.16 for proton of hydroxyl group and 11.77 for proton of the amide group. Thus, the experimentally obtained values for the dissociation constants for NClHMAH were found to be in good agreement with the computed data. From the data obtained, it is evident that NClHMAH is a dibasic acid with two potential donor sites.

The dissociation constant values of NClHMAH were found to be lowered when compared with values of $\mathrm{N}^{\prime}$-[(2-hydroxyphenyl) methylidene] acetohydrazide (NHMAH) [8] (10.9 and 13.2). This may be due to the presence of chloro group at para position to the hydroxyl group in NClHMAH, which being an electron withdrawing group might lead to dissociation of protons easily than from NHMAH.

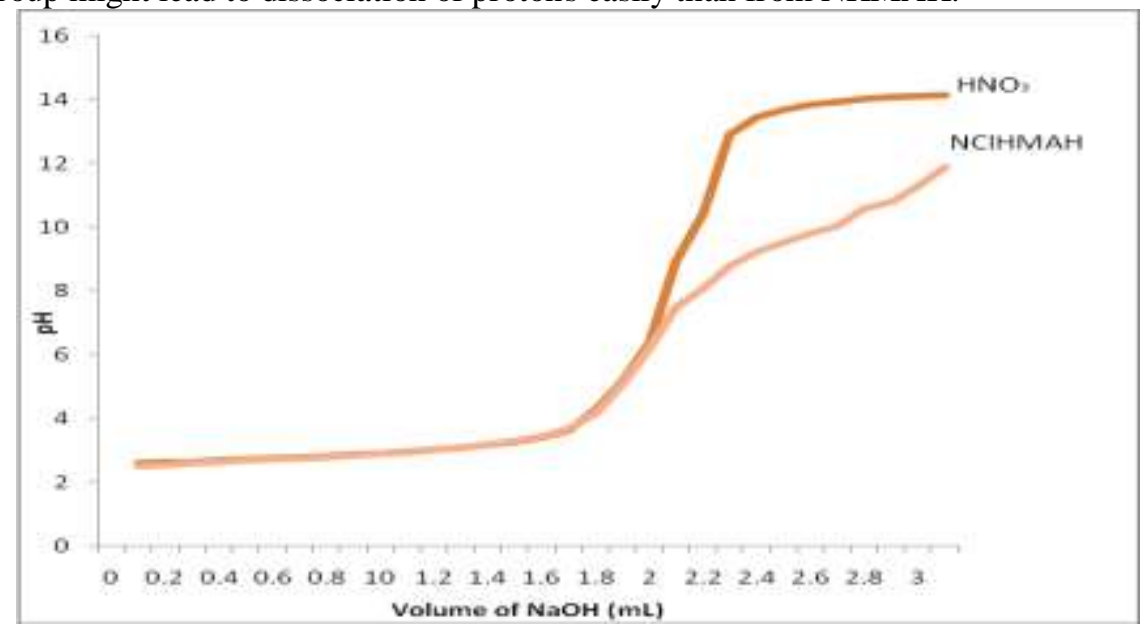

Figure $6 \mathrm{pH}$ titration curve of $\mathrm{NClHMAH}$ 
An Experimental and Theoretical Study on the Structural properties of $N^{\prime}-[(E)-(5$-chloro-2-

\subsubsection{Computational Studies}

Computational studies on NClHMAH were computed using HyperChem and ChemAxon programmes. The molecule was built using HyperChem 7.5 software and geometry optimization was done. Molecular Orbital calculations were performed with Polak - Ribiere algorithm and Parametric Method 3 (PM3) semi - empirical function. The energy parameters, Heat of Formation, Dipole Moment for the optimized geometries were calculated. (TABLE 2).

Table2: Energy parameters of NCIHMAH obtained by Semi-empirical PM3 Geometry calculations

\begin{tabular}{|l|c|}
\hline Total Energy & $-56093.05859 \mathrm{kcal} / \mathrm{mol}$ \\
\hline Binding Energy & $-2410.877686 \mathrm{kcal} / \mathrm{mol}$ \\
\hline Nuclear Energy & $236083.4531 \mathrm{kcal} / \mathrm{mol}$ \\
\hline Electronic Energy & $-292176.5 \mathrm{kcal} / \mathrm{mol}$ \\
\hline Heat of Formation $\left(\mathrm{H}_{\mathrm{f}}\right)$ & $-29.8416 \mathrm{kcal} / \mathrm{mol}$ \\
\hline Dipole moment & $5.211 \mathrm{Debye}$ \\
\hline
\end{tabular}

The electron density surfaces of Highest Occupied Molecular Orbitals (HOMO) (Fig 7a, 7b) and the Lowest Unoccupied Molecular Orbitals (LUMO) (Fig 8a, 8b), generated from the calculations are displayed below.

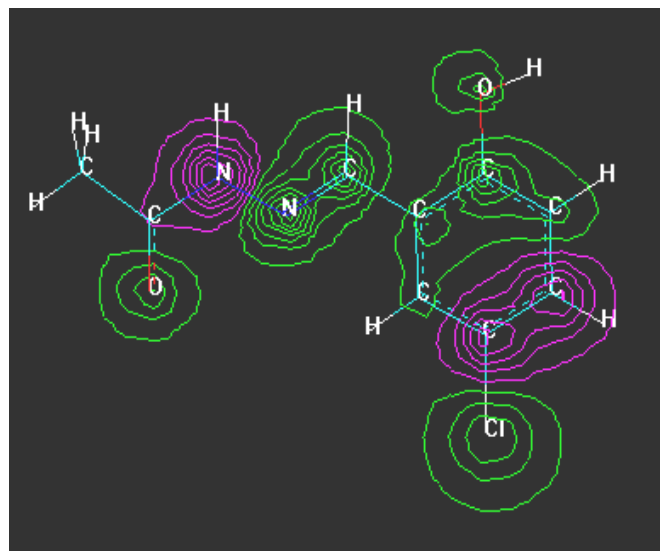

Figure 7 (a) Keto - HOMO

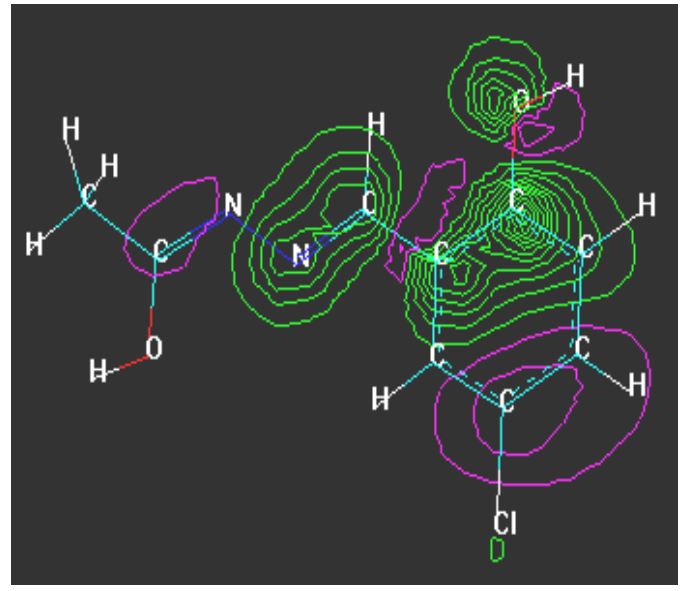

Figure 8

(a) Enol - HOMO

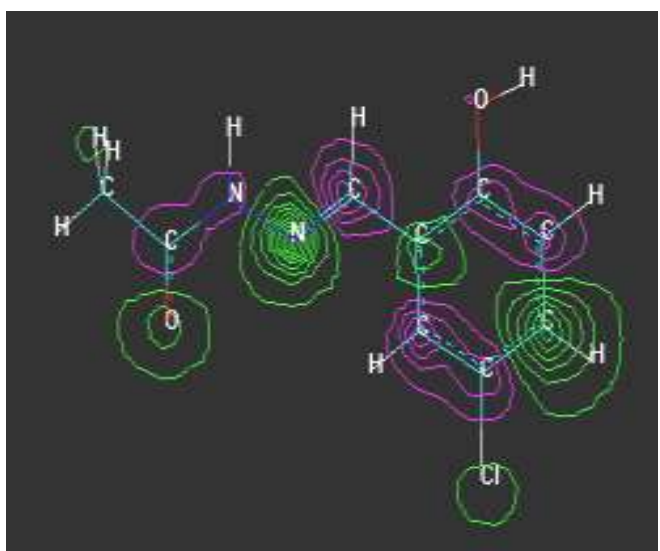

(b) Keto - LUMO

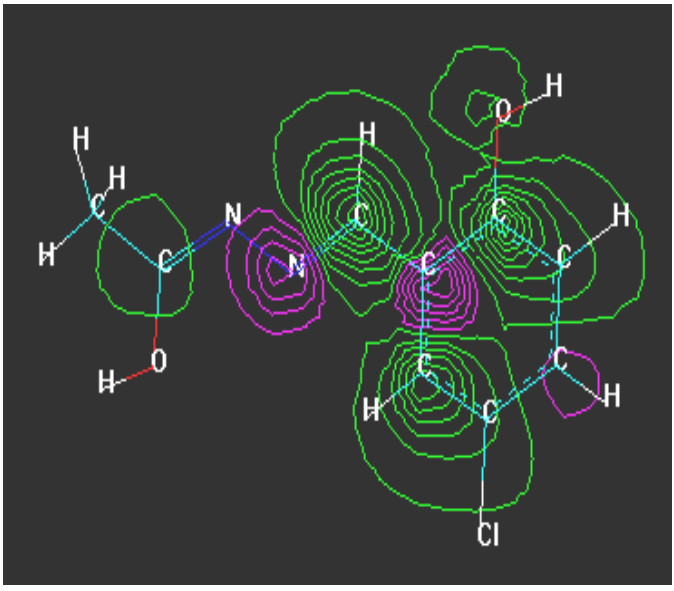

(b) Enol - LUMO

The energy of the Highest Occupied Molecular Orbital (HOMO) and the Lowest Unoccupied Molecular Orbital (LUMO) were calculated and the electron density surfaces of HOMO and LUMO of the keto and enol forms generated from the calculations for the neutral molecule in ground state have been displayed. The above figures suggest that the HOMO and LUMO orbitals are localized at the carboxy hydrazone group of the ligand. The energies and eigen values of HOMO in both keto and enol forms are comparable, but there is variation in the dipole moments and eigen values of LUMO in both the forms (TABLE 3). 
An Experimental and Theoretical Study on the Structural properties of $N^{\prime}-[(E)-(5$-chloro-2-

\begin{tabular}{|c|c|c|c|c|c|}
\hline \multirow{3}{*}{ Compound } & \multirow{3}{*}{$\begin{array}{c}\text { Energy } \\
\text { (kcal/mol) }\end{array}$} & \multirow{3}{*}{$\begin{array}{c}\text { Dipole Moment } \\
\text { (debye) }\end{array}$} & \multirow{3}{*}{$\begin{array}{c}\text { Heat of } \\
\text { Formation } \\
\text { (kcal/mol) }\end{array}$} & \multirow{2}{*}{\multicolumn{2}{|c|}{ Molecular Orbitals (eV) }} \\
\hline & & & & & \\
\hline & & & & $\begin{array}{l}\text { HOMO } \\
\text { (MO:37) }\end{array}$ & $\begin{array}{c}\text { LUMO } \\
\text { (MO: 38) }\end{array}$ \\
\hline Keto form & -56093.0586 & 5.2114 & -29.84 & -8.682362 & -0.460536 \\
\hline Enol form & -56090.4566 & 1.6627 & -27.24 & -8.657424 & -0.504767 \\
\hline
\end{tabular}

The NMR studies indicated the existence of the title compound in more than one conformational form. Studies using ChemAxon software revealed the possibility of existence of seven conformation forms in the keto form and ten in the enol form. The energy difference between the conformers of both the forms was found to be small. The energies of all the conformers are given in the TABLE 4. The figures of the highest (Fig 9) and lowest (Fig 10) energy conformers of both keto and enol forms are displayed.

Table 4: Energies of various conformers of keto and enol forms of NCIHMAH

Keto form

Enol form

\begin{tabular}{|c|c|c|c|}
\hline Conformer & Energy (kcal/mole) & Conformer & Energy (kcal/mole) \\
\hline Conf: 1 & 26.40 & Conf: 1 & 25.18 \\
\hline Conf: 2 & 26.98 & Conf: 2 & 25.29 \\
\hline Conf: 3 & 27.10 & Conf: 3 & 25.55 \\
\hline Conf: 4 & 27.68 & Conf: 4 & 25.85 \\
\hline Conf: 5 & 27.69 & Conf: 5 & 25.88 \\
\hline Conf: 6 & 28.28 & Conf: 6 & 25.99 \\
\hline \multirow[t]{4}{*}{ Conf: 7} & 28.32 & Conf: 7 & 26.15 \\
\hline & & Conf: 8 & 26.15 \\
\hline & & Conf: 9 & 26.25 \\
\hline & & Conf: 10 & 26.43 \\
\hline
\end{tabular}

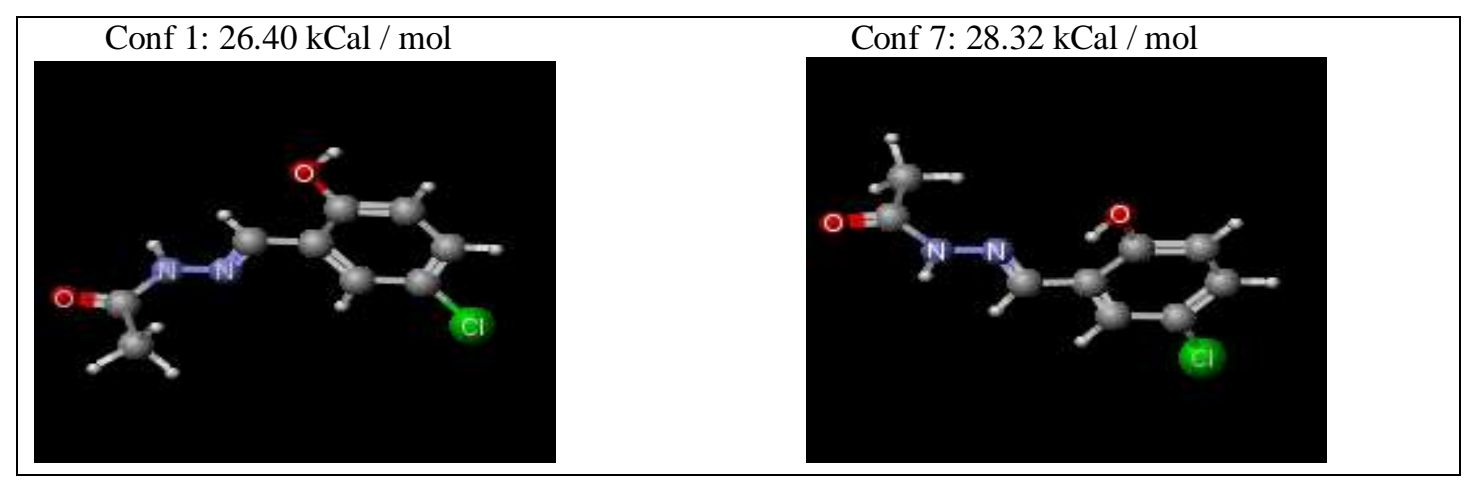

Figure 9 Conformers with lowest \& highest energies of the Keto form

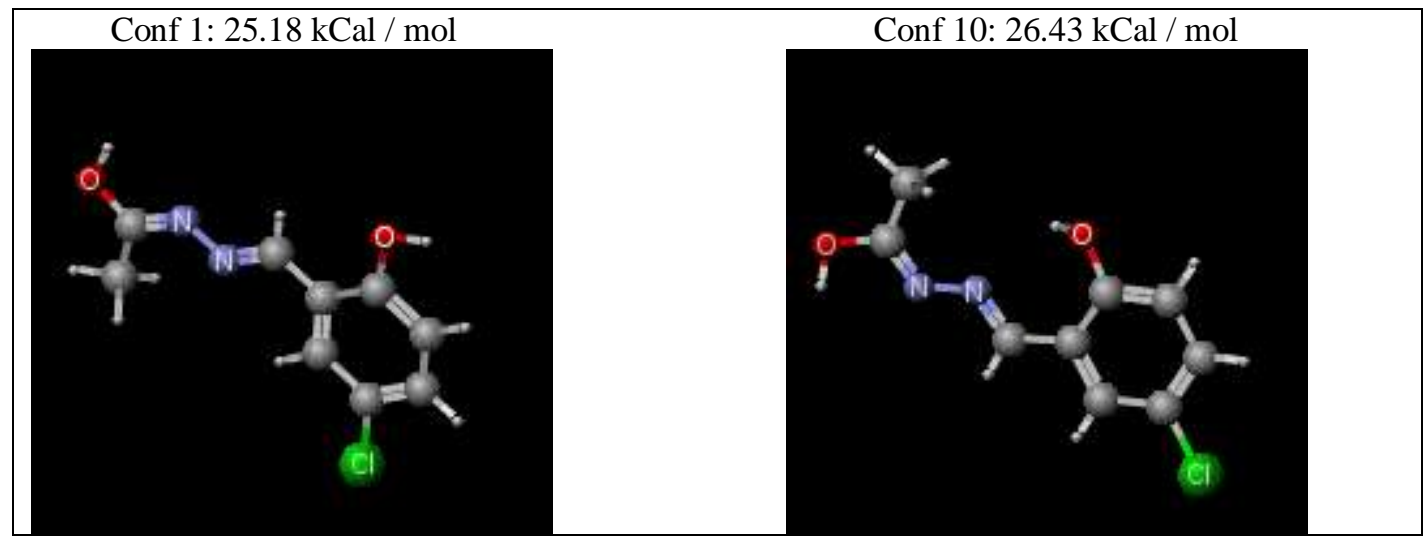

Figure 10 Conformers with lowest \& highest energies of the Keto form 


\subsubsection{QSAR studies}

An attempt is made to study the physico-chemical properties of N'-[(E)-(5-chloro-2hydroxyphenyl)methylidene] acetohydrazide by employing Quantitative Structure Activity Relationship (QSAR) studies. Properties like Surface Area, Volume, Polarizability, Refractivity, $\log$ P values and variuos energy parameters (TABLE 5) have been calculated using Parametric Method 3 (PM3).

Table 5: QSAR properties of NCIHMAH obtained by Semi - Empirical PM3 Geometry calculation

\begin{tabular}{|c|c|}
\hline Surface Area & $389.31 \check{\mathbf{A}}^{2}$ \\
\hline Volume & $624.60 \mathbf{\AA}^{3}$ \\
\hline Hydration Energy & $-10.48 \mathrm{kcal} / \mathrm{mol}$ \\
\hline Refractivity & $52.86 \check{\AA}^{3}$ \\
\hline Polarizability & $20.87 \check{\AA}^{3}$ \\
\hline Log P & 5.03 \\
\hline
\end{tabular}

\subsection{Spectral characterization of the complex}

Copper complex of the title compound has been synthesized and was characterized by spectral techniques such as Mass, IR, Elemental analyses and Thermo gravimetric studies.

\subsubsection{LC - MS Data}

The LC chromatogram showed a single peak at 0.552 mins (negative mode). The mass spectrum of the complex shows a dominant base peak at $\mathrm{m} / \mathrm{z} 291$. This molecular mass indicates the complex with 1:1 metal ligand ratio with a coordinated water molecule (Fig 11).

Earlier studies with $\mathrm{N}^{\prime}$-[(2-hydroxyphenyl) methylidene] acetohydrazide (NHMAH) [8] reported the formation of the dinuclear copper complex $[\mathrm{Cu}-(\mathrm{NMA})]_{2}$. While in the present system, formation of mononuclear complex with coordinated water is evident. However in both the systems the metal to ligand ratio is $1: 1$.

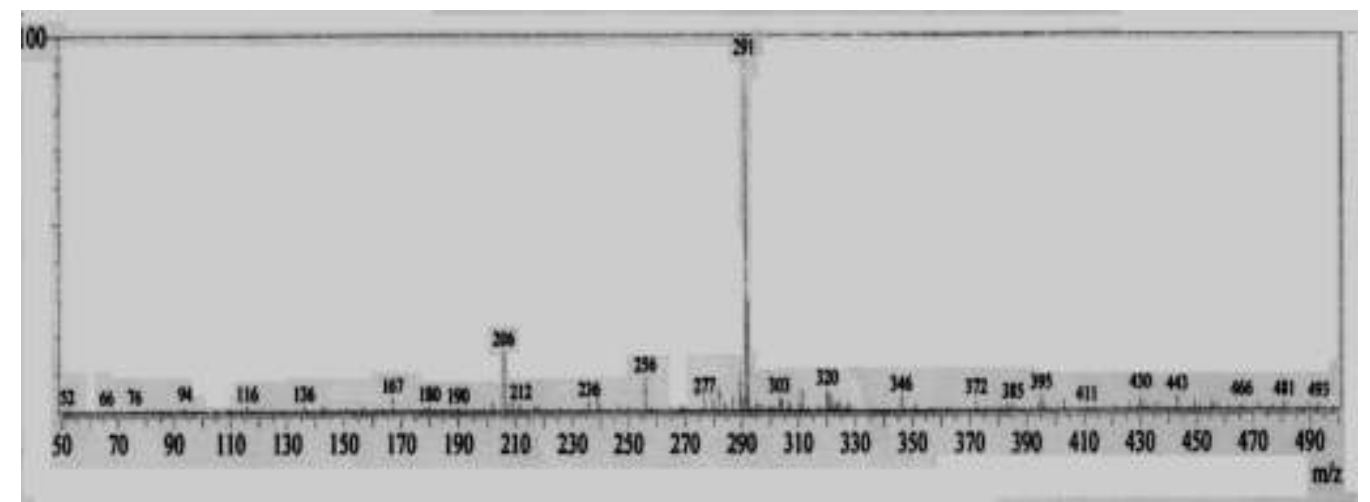

Figure 11 Mass spectrum of the copper complex

\subsubsection{IR Data}

The IR spectrum of the complex (Fig 12) was recorded and compared with the ligand spectrum to study the changes in ligand upon complexation. Due to the binding of the ligand with the metal ion, $v_{\mathrm{O}-\mathrm{H},} v_{\mathrm{N}-\mathrm{H}}$ and $v_{\mathrm{C}=\mathrm{O}}$ peaks seen in the IR spectrum of the ligand disappear in the spectrum of metal complex. Thus, the coordination of specific donor sites with metal ion through deprotonation can be identified.

The IR spectrum of the ligand showed the presence of peaks $v_{\mathbf{O}-\mathrm{H}}\left(3836 \mathrm{~cm}^{-1}\right), v_{\mathrm{C}=\mathbf{N}}\left(1627 \mathrm{~cm}^{-1}\right)$ and $v_{\text {CONH }}\left(1664 \mathrm{~cm}^{-1}\right)$. The appearance of a trough in the range of $3100-3500 \mathrm{~cm}^{-1}$ indicates the presence of coordinated water molecule. Disappearance of strong peak at $1664 \mathrm{~cm}^{-1}$, indicated the involvement of oxygen of carbonyl group in the complex formation.

In the IR spectrum of the free ligand, a peak appears at $1627 \mathrm{~cm}^{-1}$ corresponding to $v_{\mathrm{C}=\mathrm{N}}$ of azomethine group. A slight shift in the peak towards lower wave number side, $1624 \mathrm{~cm}^{-1}$ was observed. This indicates the coordination of azomethine nitrogen with the metal ion. Appearance of peak at $1529 \mathrm{~cm}^{-1}$ indicates formation of diimine (-C=N-N=C-) group [9]. Medium intensity peaks at 1406 and $1369 \mathrm{~cm}^{-1}$, characteristic to methyl group were observed. Weak absorptions in the range of $3100-2800 \mathrm{~cm}^{-1}$ correspond to aliphatic and aromatic stretching frequencies. 


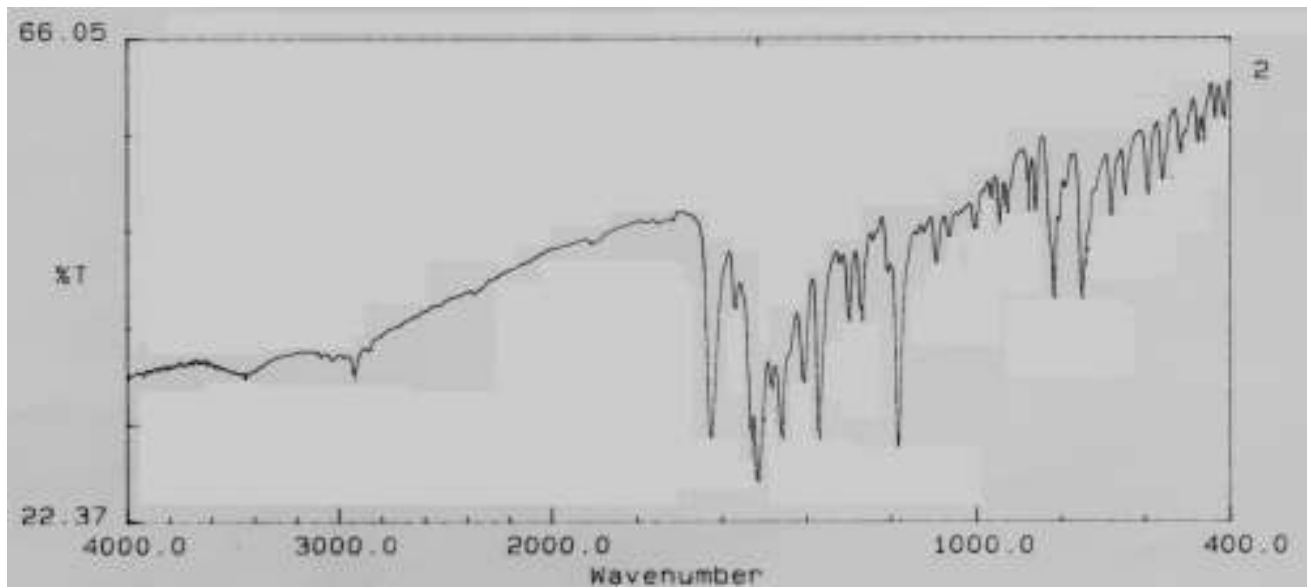

Figure 12 IR spectrum of the copper complex

\subsubsection{Thermo - analytical Methods}

Thermoanalytical studies (TGA \& DSC) were carried out on the copper (II) complex to study the weight changes associated with thermally induced transitions.

The TGA curve of the complex showed the decomposition of the metal chelate in the temperature range of $0-1200^{\circ} \mathrm{C}$. The weight loss observed in the range of $200-300^{\circ} \mathrm{C}$ might be probably due to the loss of coordinated water molecule. The weight loss in the range of $340-1200{ }^{\circ} \mathrm{C}$ might be due to the gradual decomposition of the metal complex. The loss or gain of the energy involved during the physical transformation of the sample is measured by DSC and this is indicated by appearance of endothermic (absorption of energy) and exothermic peaks.

\subsection{Biological Studies}

The title compound and its metal complex were tested for anti-bacterial activity [10-15] against a set of bacterial stains, namely, Escheriachia Coli and Staphylococcus aureus.

Agar diffusion method is employed to test the sensitivity of the test bacterial cultures to the compound in terms of inhibition of their growth. Such a compound thus is called "Anti-bacterial Agent". The extent of inhibition of the bacterial growth is determined in the form of diameter of the inhibition zone.

Agar diffusion method is carried out by inoculating overnight broth of test culture on a basal medium. Spread plate method is used to get carpeted growth which gets inhibited if it is susceptible to the test compound. The solution of the antimicrobial compound is loaded in the wells or on the filter paper disc. The antibacterial substance diffuses in the agar and thus inhibits the growth of actively growing bacterial cells.

The solutions were prepared using Dimethyl Sulphoxide (DMSO). The reason for choosing DMSO for anti-bacterial studies was that, it has no effect on the above mentioned bacterial stains.

Protocol: Test cultures
Escheriachia Coli $\quad-$ Gram Negative
Staphylococcus aureus - Gram Positive

Pure cultures are obtained from National Collection of Industrial microorganisms NCIM, NCL, CSIR lab, Pune. Maintenance of the cultures: The bacteria are maintained on Nutrient Agar (Himedia, India) slopes at $4^{\circ} \mathrm{C}$ and subcultured as per the requirement.

Determination of the Anti-bacterial Activity:

1. Invitro antibacterial activity of the test compounds is carried out by Agar Diffusion Method using Mueller Hinton medium. The compounds used were of $100 \mu \mathrm{g} / \mu \mathrm{L}$ concentration.

2. The overnight broth of the inoculation is seeded on the agar plate $\left(1.5 \times 10^{8} \mathrm{CFU} / \mathrm{mL}\right)$.

3. Wells are prepared in seeded agar plates with $8.5 \mathrm{~mm}$ diameter and test samples are introduced in each well.

4. Solvent used for preparing samples is DMSO.

5. Solvent control was run for every assay.

6. All the plates are incubated at $37^{\circ} \mathrm{C}$ for $24 \mathrm{hrs}$.

7. The antibacterial spectrum of the test sample is determined in terms of "zone sizes" around each well i.e; diameter of the inhibition zones.

8. Each result is a mean of two replicates. 


\subsubsection{Observations}

\begin{tabular}{|c|c|c|}
\hline & Test sample and Concentration & $\begin{array}{c}\text { Zone of Inhibition } \\
\text { Diameter (mm) }\end{array}$ \\
\hline Escheriachia Coli & NClHMAH, $100 \mu \mathrm{g} / \mu \mathrm{L}$ & Resistant \\
\hline & $\mathrm{Cu}(\mathrm{II}) \mathrm{NClMA}, 100 \mu \mathrm{g} / \mu \mathrm{L}$ & 20 \\
\hline
\end{tabular}

\begin{tabular}{|c|c|c|}
\hline & Test sample and Concentration & $\begin{array}{c}\text { Zone of Inhibition } \\
\text { Diameter (mm) }\end{array}$ \\
\hline Staphylococcus aureus & $\mathrm{NClHMAH}, 100 \mu \mathrm{g} / \mu \mathrm{L}$ & 11 \\
\hline & $\mathrm{Cu}(\mathrm{II}) \mathrm{NCIMA}, 100 \mu \mathrm{g} / \mu \mathrm{L}$ & 22 \\
\hline
\end{tabular}

The results suggest that moderate antibacterial activity was shown by NClHMAH against Staph. Aureus and the compound is resistant to E.Coli. The copper complex has exhibited great anti - bacterial activity for both the cultures.

\subsection{Conclusions}

The structural aspects of the title compound have been studied by theoretical and experimental studies. NMR $\left({ }^{1} \mathrm{H} \&{ }^{13} \mathrm{C}\right)$ studies on the ligand revealed that the title compound exhibits conformational isomerism. The energy difference between the conformers of both keto and enol forms was found to be small. The IR and NMR studies calculated by semi - empirical PM3 method are nearly in good agreement with the obtained experimental data. Equilibrium studies carried on the ligand suggest that it is a dibasic acid and this was also indicated by ChemAxon software. Anti-bacterial studies were carried out on the title compound and it was found that the compound was resistant to gram negative bacteria while moderate activity was observed for gram positive bacterial culture.

Copper (II) complex of the hydrazone was also synthesized and characterized by spectral techniques. The mass spectrum of the complex showed the presence of a coordinated water molecule. This was further supported by thermo - analytical studies. The IR spectral data provided information regarding the donor sites for the formation of complex. Copper complex exhibited a very good anti - bacterial activity against both the cultures.

The electron density figures of HOMO and LUMO of NHMAH support the suitability of molecular orbitals oriented along carboxy hydrazone moiety for bonding with metal ion.

Thus, it can be concluded that the theoretical data is useful for analyzing the experimental data.

\section{References}

[1] Sevim Rollas and S. Guniz Kucukguzet, Biological Activities of Hydrazone Derivatives, Molecules, 2007, 12,1910 - 1939

[2] Jonathan R. Dimmock, Sarvesh C. Vashistha, James P. Stables, Anticonvulsant properties of various acetylhydrazones, oxamoylhydrazones and semicarbazones derived from aromatic and unsaturated carbonyl compounds, Eur. J. Med. Chem., 2000, $35,241-248$.

[3] B.S. Furniss, A.J. Hannaford, P.W.G. Smith, A.R. Tatchell, Vogels text book of practical organic chemistry (5 ${ }^{\text {th }}$ edition)

[4] ChemAxon, http://www.chemaxon.com

[5] Hyperchem, 2003, Hypercube, Inc

[6] Irving H.M, Rossotti H.S, The calculation of formation curves of metal complexes from pH titration curves in mixed solvents, J.Chem. Soc., 1954, 2904.

[7] G. Srineevas Reddy, B. Sireesha, Ch. Sarala Devi, Rafeeq, Gyana Kumari and M.G. Ram Reddy. Interaction of Nickel-, Cobalt-, Zinc- and Lead(II) with Benzothiazole-2-Carboxyhydrazides in solution: Synthesis of their Copper (II) complexes $J$. Indian. Chem. Soc., 1998, 75, 290-292.

[8] A.V.Aparna, K.Sudeepa, Ch.Sarala Devi and Raghavaiah Pallepogu, Spectro - Analytical, X-Ray Diffraction and Computational Studies on $\mathrm{N}^{\prime}$-[(2-hydroxyphenyl) methylidene] acetohydrazide and its copper complex, J.Indian Chem. Soc, (In Press)

[9] S.C. Chan, L.L Koh, P.H. Leung, J.D. Ranford, K.Y. Sim, Copper(II) complexes of antitumour-related ligand salicylaldehyde acetylhydrazone $\left(\mathrm{H}_{2} \mathrm{~L}\right)$ and the single-crystal X-ray structures of $\left[\left\{\mathrm{Cu}(\mathrm{HL}) \mathrm{H}_{2} \mathrm{O}\right\}_{2}\right] \cdot 2\left(\mathrm{NO}_{3}\right)$ and $\left[\left\{\mathrm{Cu}(\mathrm{HL})(\mathrm{pyridine})\left(\mathrm{NO} \mathrm{O}_{3}\right)\right\}_{2}\right]$, Inorganica Chimica Acta, 1995, 236, 101.

[10] Benson, Microbiological Applications - Laboratory manual in General Microbiology (Mc. Graw Hill Publication, Eighth edition, 2002).

[11] Monica Cheesbrough, Medical Laboratory Manual for Tropical Countries Volume II Microbiology (English Language Book Society, Second Edition, 1985).

[12] Cappuccino and Sherman, Microbiology - A laboratory manual (Pearson Edition Publisher, 2002).

[13] Jeffrey C. Pommerville, Alcamo's Laboratory Fundamentals of Microbiology (Jones and Bartlett Publishers, Seventh Edition, 2005).

[14] George A Wistreich and Max D. Lechtman, Laboratory Exercises in Microbiology (Prentice Hall Publications, Sixth Edition, 1988).

[15] M. Gopal Reddy and et al., Laboratory Experiments in Microbiology (Himalaya Publishing House, First Edition, 2005). 